\title{
A Situational Theory of Advantages in Sport
}

Authors' contribution:

A) conception and design of the study

B) acquisition of data

C) analysis and interpretation of data

D) manuscript preparation

E) obtaining funding

\section{Mika Hämäläinen}

University of Turku, Finland

\section{KEYWORDS}

\begin{abstract}
The purpose of this paper is to provide a systematic explanation of the concept of advantage in the context of sport competitions. Advantage is a common concept in sports, but it also holds ambiguities that need clarification. Let's say, for example, that the national soccer team of Brazil is playing the national team of Finland and is ahead 5 to 0 . Finland receives a penalty kick due to a refereeing error. At this point, which of the teams has the advantage? In this paper, I answer this question through a systematic explanation of the concept of advantage. My theory is based on Sigmund Loland's view that advantage can be distributed both formally and informally in sport competitions. I will develop Loland's notion of formal advantage by introducing what I call an absolute sense of advantage - a relation of superiority that is based on the performances of two competitors. I replace informal advantage with what I refer to as an expectancy sense of advantage, which is related to expectations regarding the absolute advantage. These two senses of advantage have different functions, and I conclude that advantage is a phenomenon that plays a vital role in all sport competitions through these two senses - absolute and expectancy.

athletic performance, competition, Oscar Pistorius, unfair advantage
\end{abstract}

\section{Introduction}

Advantage is a concept that is frequently used in a sports context in a straightforward manner. For instance, a basketball team can gain an advantage through arduous training or a middle-distance runner can gain advantage by an explosive sprint on the final stretch. However, the concept is more ambiguous and complex than it initially appears. Imagine a soccer match between the national teams of Brazil, which is one of the most successful soccer teams worldwide, and Finland, which has never managed to reach the World Cup Finals. Brazil leads Finland 5-0 after 80 minutes of play, and then Finland receives a penalty kick due to a refereeing error. Has the Finland team gained an advantage, or does the Brazil team still have the advantage because it is so far in the lead? This scenario shows how the concept of advantage, which initially appears to be straightforward, can conceal conflicting intuitions.

It is important to map out the contradictions surrounding the concept of advantage since it has played a significant role in several heated sport-related incidents. For instance, for some months in 2008, Oscar Pistorius was not allowed to participate in able-bodied contests. The ban stemmed from empirical research results that indicated that Pistorius had an advantage due to his carbon-fiber prostheses (see Brüggemann, 
Arampatzis, Emrich \& Potthast). The case of Caster Semenya is similar. She is a female athlete whose sex was challenged after she won the 800-meter World Championships in 2009. In both of these cases, philosophers of sport have analyzed which advantages are unfair and which are not, but they have mainly ignored the ambiguity of the concept of advantage (Foddy \& Savulescu, 2011; Edwards, 2009; Jones \& Wilson, 2009; see also Carr, 2008; Gardner, 1995). If we ground our moral evaluations on concepts of an ambiguous nature without sufficient clarification, then our decisions may not be valid or fair.

The aim of this paper is to analyze the different meanings of advantage and to present a systematic explanation of this concept ${ }^{1}$. I try to achieve this end by developing Sigmund Loland's view of advantage, since he has provided the most in-depth analysis of this concept to date $(1999 ; 2002 \text {, pp. 84-87 })^{2}$. There are a few other studies that touch upon advantage in the realm of sports, but they have not been as extensive (see Court of Arbitration for Sport, 2008, pp. 10-11; Gardner, 1995, p. 223; Jones \& Wilson, 2009, pp. 125-127).

I begin by presenting what Loland calls the "structural goal of sport competitions." This leads us to his view of advantage, which he classifies as formal and informal. I discuss formal advantage and develop it further into what I call an absolute sense of advantage. Then, I discuss the concept of informal advantage, which I develop into what I call the expectancy sense of advantage. After this, I elaborate upon the relationship between the absolute sense and the expectancy sense of advantage. Finally, I draw the conclusion that advantage is a phenomenon of superiority that plays a vital role in all sports competitions. I also apply my model to a hypothetical match between Brazil and Finland.

\section{The structural goal of sport competitions}

Loland's view of advantage is part of his theory of fair play (Loland, 2002). An important building block of this theory is the structural goal of sports competitions. He writes, "The goal of sport competitions is to measure, compare and rank two or more competitors according to athletic performance" (italics added; Loland, 2002, p. 10). In a marathon race, for example, the goal is to reach the finish line as quickly as possible. First, we measure the time the competitors spent running. Next, we compare the time of each athlete. Finally, we rank the competitors according to their times. The process of measuring, comparing, and ranking occurs during the whole competition, and the rankings at the end of the competition ultimately decide the winner. In brief, measuring, comparing, and ranking are based on athletic performance (Loland, 2002, pp. 9-10).

Loland connects the structural goal of sport competitions with advantage as follows: "Measurements, comparisons and rankings of athletic performance are carried out via the distribution of advantage" (Loland, 2002 , p. 84). In other words, the structural goal of sport competitions is achieved through the distribution of advantages. Loland asserts that the distribution can be formal or informal (Loland, 1999, pp. 169-170; 2002, p. 85). I begin by discussing formal advantage.

\section{Formal advantage}

According to Loland, formal advantage is based on the rules of each sport and may occur during or at the end of the competition. Furthermore, it can be awarded in physical-mathematical units or in sportspecific units (Loland, 2002, pp. 85-86).

\footnotetext{
${ }^{1}$ I have argued elsewhere that there are two kinds of advantage: performance advantage and property advantage (Hämäläinen, 2012). In this paper, I present a similar thesis that there are two senses of advantage but claim that these are an absolute sense and an expectancy sense. Despite this obvious difference, my previous and current attempts to systematize the concept of advantage are perhaps best described as complementary, since absolute advantage and expectancy advantage can be conceived subcategories of performance advantage.

${ }^{2}$ Loland's view is practically same in both of his texts, but his terminology differs slightly. I use terms from his 2002 publication. In addition, most references are from this source, since Loland's explanation is generally more comprehensive in that text.
} 
Advantage concerning physical-mathematical units. Examples that Loland provides for the physicalmathematical distribution of advantage include a 1,500-meter run, the long jump, and weight lifting. Runners gain an advantage in seconds, jumpers in meters, and weight lifters in units of mass. Further, Loland provides a concrete example from a track-and-field event: "Javelin thrower $\mathrm{X}$ is in the lead after three throws with a distance of 67.15 metres'; 'Javelin thrower Y won with a throw of 72.50 metres'" (Loland, 2002, p. 85). This example describes how Javelin Thrower $X$ was leading the competition, which was eventually won by Participant Y. Unfortunately, Loland does not explicate how advantage instantiates in his example, nor does he provide an explicit definition that could be applied to concrete cases. Together, these omissions leave his view of sport-specific advantage vague. However, these shortcomings can be ameliorated to some extent.

When our starting point is Loland's theory, formal advantage can be seen as a combination of measuring, comparing, and ranking. This is based on his claim mentioned above that "measurements, comparisons and rankings of athletic performance are carried out via the distribution of advantage" (Loland, 2002, p. 84). I interpret this statement to mean that measuring, comparing, and ranking can be depicted as three separate steps to be taken. Together, these steps describe the phenomenon of the formal advantage. An example from the track-and-field event of javelin throwing clarifies my viewpoint.

In the 2005 Osaka World Championships, Finnish javelin competitor Tero Pitkämäki won with a throw of 90.33 meters, and Norwegian competitor Andreas Thorkildsen placed second with a throw of 88.61 meters. The performances of the Finn and the Norwegian can be deconstructed as follows. Pitkämäki's throw was 90.33 meters, and Thorkildsen's throw was 88.61 meters; this constitutes measuring. Next, we can note that Pitkämäki's throw was 1.72 meters longer than Thorkildsen's throw, which is comparing. Finally, Pitkämäki's throw was better than Thorkildsen's throw because in the sport of javelin, one tries to throw the instrument as far as possible. This is ranking. This example illustrates that advantage is a combination of three steps: measuring, comparing, and ranking.

These three steps are interdependent in that the last step requires all of preceding steps. We cannot make a comparison unless we have numbers to compare, and we cannot rank unless we are able to find difference between numbers. In other words, ranking utilizes the two previous steps of measuring and comparing. Therefore, we could speak merely about ranking or "betterness" because it implies measuring and comparing. I will employ this strategy later in this paper.

It should be emphasized that the deconstruction of formal advantage into these three steps does not show how people actually process the situation in their mind. In real life, we can see rankings instantly because we use a kind of shortcut inference: The spectators were immediately able to rank Pitkämäki's throw as better than Thorkildsen's throw without consciously processing the three steps. An explanation of this mismatch is that the three-step deconstruction process is not meant to be an iconic representation of an actual mental process. It is an analytic exposition that can be applied in the context of any sports competition. An analogous example might clarify my point.

Suppose that you have to answer a multiplication question, such as "What is $5 \mathrm{x} 5$ ?" You will most likely instantly say " 25 " because you memorized this answer many years ago. In contrast, if you are asked to justify your answer, you can explain that the result is the summation of " $5+5+5+5+5$." However, this justification does not represent your original mental process. Originally, you simply remembered the answer. In conclusion, a mental process may lead to a result that is not justified by referring to this mental process but rather by a reference to something else.

Sport-specific advantage. Loland asserts that sport-specific advantage instantiates inter alia in tennis, basketball, pistol shooting, soccer, and handball. Yet, these sports have slightly different types of sportspecific units. In tennis, formal advantage concerns games and sets; in basketball and pistol shooting, competitors try to achieve points; and in soccer and handball, they strive for goals (Loland, 2002, p. 86).

Loland describes that sport-specific advantage can occur both during and at the end of the competition. For instance, a soccer team may have a lead of two goals during the match. According to Loland, the winner 
is decided in the following manner: "At the end of the competition, sport-specific advantages are accumulated and determine the final ranking" (Loland, 2002, p. 86). This accumulation of advantages can be referred to as counting. A soccer team wins if it has scored four times and its opponent has scored twice.

Formal advantage is a combination of measuring, comparing, and ranking in the case of sport-specific advantage, as it was in the context of physical-mathematic units of advantage. This can be illustrated with an example of a soccer match. Argentina and West Germany met in the World Cup Finals in Mexico in 1986. After two-thirds of the game had been played, the score was in favor of Argentina, 2-0. In other words, Argentina had gained a sport-specific advantage; the measurements of the teams' performances were 2 and 0 for Argentina and West Germany, respectively. Subsequently, it is a comparison to say that 2 goals is 2 more than 0 . More goals are better than fewer goals in the game of soccer. Therefore, 2 goals are better than 0 goals, which is ranking. In conclusion, Argentina had gained a sport-specific advantage.

Altogether, Loland states that formal advantage can be distributed both in physical-mathematical units and in sport-specific units. Furthermore, I suggest that Loland conceives formal advantage as a union of measuring, comparing, and ranking athletic performances. Notwithstanding, we do not have an actual definition that thoroughly states what formal advantage is. What we have is Loland's taxonomical classifications and my general characterization. Next, I attempt to ameliorate the situation by proposing an improved version of Loland's definition of formal advantage.

\section{From formal advantage to an absolute sense of advantage}

I believe that this concept can be more accurately defined by renouncing Loland's use of the term "formal advantage" and replacing it with what I call the absolute sense of advantage, which depicts a relationship of superiority. The exact definition is as follows: Competing party A has absolute advantage over competing party $\mathrm{B}$ at a certain point of a sport competition if $\mathrm{A}$ has a better performance number than $\mathrm{B}$ at that point of the competition.

For instance, Thorkildsen had an absolute advantage over Pitkämäki at the end of the javelin final at the 2008 Beijing Olympics. In this contest, the Norwegian won and the Finn placed third. The Olympic gold medalist threw the javelin 90.57 meters, and the Olympic bronze medalist threw the javelin 86.16 meters. Respectively, their performance numbers were 90.57 meters and 86.16 meters. From these two performance numbers, 90.57 meters is better. Therefore, Thorkildsen had absolute advantage over Pitkämäki at the end of the competition.

A second example is the duel between Argentina and West Germany in the World Cup Final in 1986. Argentina eventually won the match. It had a performance number of 3 goals, whereas West Germany's performance number was 2 goals. Argentina thus had an absolute advantage over West Germany at the end of the match because 3 goals are better than 2 goals.

My definition has two components that require further elaboration-performance number and reference to a certain point of a sports competition. First, performance number is a number based on a certain scale. In a 100-meter race, the performance number is based on a scale of time; for javelin throwing, the performance number is based on a scale of length; and for figure skating, the performance number is based on a scale of points.

The performance number covers both main categories of formal advantage-physical-mathematical advantage and sport-specific advantage. Therefore, the classification between these categories appears to be extraneous. Instead of referring to physical-mathematical and sport-specific units of advantage, we can use a single term of their upper category, which I have labeled performance number.

The performance number is ascribed to a relevant aspect of athletic performance, which is thought to represent the whole performance. Thus, we do not primarily measure, compare, and rank athletic performances, per se, as Loland (2002, p. 10) seems to suppose; rather, we are primarily evaluating a specific 
aspect of performances. My claim can be elaborated in the context of the 100-meter final of the Berlin World Championships in 2009.

Usain Bolt and Tyson Gay both participated in this race. To measure this race, it seems obvious that we would measure the time that the athletes took to reach the finish line. Bolt set a new world record of 9.58 seconds, while Gay's time was 9.71 seconds. However, we can also measure other aspects of the performances, such as reaction time, top speed, stride frequency, or stride length. Numerically, Bolt's reaction time was 0.144 seconds and Gays was 0.146 seconds. Bolt reached a top speed of $44.72 \mathrm{kph}$, while Gay's top speed was determined to be $44.17 \mathrm{kph}$ (IAAF, 2009; Tucker \& Dugas, 2009). We can compare all these aspects as well. Bolt's final time was 0.13 seconds shorter than Gay's time; his reaction time was 0.002 seconds slower than Gay's, and his top speed was $0.55 \mathrm{kph}$ higher than Gay's. Finally, we can rank performance according to these different aspects. Gay had a better reaction time than Bolt, but Bolt had a better final time and top speed. Hence, by emphasizing different aspects, we may achieve different results. In conclusion, athletic performances have many aspects that we can analyze.

Among several aspects of athletic performance, the relevant factor is the one that indicates how well the sport-specific goal of a certain sport is obtained. This statement is based on Loland's (2002, p. 9) suggestion that win a particular sport, one must achieve the sport-specific goal that is defined by the constitutive rules of the game. We are interested in the winner of a particular sport. Therefore, for a 100meter race, the relevant aspect is the time spent to complete the course.

Second, reference to a certain point of a sport competition in the definition of the absolute sense of advantage is based on Loland's perspective on formal advantage. As previously mentioned, he suggests that formal advantage can occur both during and at the end of competitions (Loland, 2002, p. 85). Similarly, absolute advantage is dependent upon the point of the competition. For instance, Jamaican sprinter Asafa Powell usually explodes out of the blocks and can therefore have an absolute advantage over Bolt right after the start. However, he is not as capable of holding the lead over Bolt all the way to the finish line. In brief, we must know what point of competition we are discussing if we wish to determine whether an athlete has absolute advantage over his or her rival.

The definition of absolute advantage implies that it can vary during a sports competition. Similarly, performance numbers can be ascribed tentatively at different moments of sports competitions and are confirmed or ascribed permanently at the end. In the Berlin final, Bolt's performance number was 2.89 seconds at the 20-meter mark, and Gay's performance number was 2.92 seconds at the same point (IAAF, 2009). Bolt thus had an absolute advantage over Gay at this point of the competition.

To summarize, the absolute sense of advantage is a relationship of superiority between the numbers that represent the relevant aspects of the athletic performance of two competing parties. I initially introduced this viewpoint of advantage to amend Loland's notion of formal advantage because he was more interested in taxonomies related to formal advantage than defining it. Next, I examine the other kind of advantage that Loland discusses_-informal advantage.

\section{Informal advantage}

Loland claims that "gaining an informal advantage implies achieving a position in the process of competing in which the possibilities for formal advantage improve" (italics added; Loland, 2002, p. 85). He illustrates that if a soccer player dribbles around an opponent and achieves a good position for a shot, she has increased her chances of scoring a goal and has therefore gained informal advantage (Loland, 2002, p. 86). Hence, informal advantage means an increased probability of formal advantage. In contrast to formal advantage, however, informal advantages are not described in the rules of a particular sport (Loland, 2002, pp. 85-86).

There are two criticisms of this view. First, we do not have direct access to improved possibilities. Loland's example of the dribbling player illustrates this since the player's chances of scoring a goal might 
not have actually increased. She may become so nervous about the open space and the expectations of others that her chances of scoring conversely decrease. This would then not be an instance of informal advantage. I admit that these kinds of situations are very uncommon-athletes only rarely "freeze" in this kind of situation. It is also noteworthy that when the possibility of scoring a goal increases, the amount of increase also varies. If the player is Lionel Messi, Christiano Ronaldo, or Mario Balotelli, then the chances of scoring are higher than if the player is from a lower league. In conclusion, after dribbling around an opponent and achieving a good position for a shot, the possibilities of a goal will most likely improve but can sometimes decrease.

I think that Loland had good reason to suggest that the chances of scoring a goal are improved if the player dribbles around an opponent and moves into a good position for a shot. The reason is Loland's past experience. His suggestion exemplifies induction, as he has predicted future events from past events. To simplify, I suppose Loland has witnessed how players have scored frequently under certain circumstances. Therefore, he infers that dribbling around an opponent and moving into similar positions increases the possibility of the player scoring a goal. In other words, it was reasonable for Loland to expect that a player has improved the possibility of a goal because he has perhaps not seen players freeze in this context. There are other possible, if unlikely, exceptions in this context that Loland has not taken into consideration. For instance, a bird, such as an eagle owl, might fly onto the field and interrupt the plans of the attacker when he comes to close to the goal ${ }^{3}$.

Loland's use of soccer as an example shows that our reasonable expectations can be misguided. The success of induction is based on the assumption that the world is regular in a stable manner and that we have observed a representative piece of the world's regularity. The more exceptions there are and the more we have missed them, the more vulnerable our reasoning is. If we are not conscious of the exceptions, then we cannot take them into account when forming our reasonable expectations. In other words, possibilities may improve or decrease independently from our reasonable expectations about them.

The more general the induction is, the more apt it is to fail. One can reasonably expect that Lionell Messi increases his possibilities of scoring a goal if he dribbles around a defender and achieves a good position without any interrupting animals, such as eagle owls. This holds better than a more general expectation that a player increases his or her chances of scoring a goal if he or she dribbles around an opponent and moves into a good position for a shot. However, the more general the induction is, the more informative it usually is. The claim about Messi is rather uninformative, but the general expectation is more useful.

The second problem of Loland's notion of informal advantage concerns its relevancy: Informal advantage elevates the wrong aspect of competition from the viewpoint of advantage. In other words, Loland is right when he maintains that informal advantage improves the possibility of a formal advantage, but his claim is not informative in a way that the concept of advantage should be. Advantage should inform us about the relative superiority of competitors. From Loland's perspective, a competitor has gained an informal advantage if his or her possibilities for gaining a formal advantage have improved. However, this does not reveal his or her relation to the other competitors. For instance, running behind a competitor in a track event helps with headwind, but it does not indicate the likelihood that the tactical runner is going to outperform his or her rival. Although we would know that his or her probabilities have increased, we cannot infer to which level they have increased. Instead, the aspect of outperforming is relevant to the concept of advantage.

These two criticisms of Loland's notion of informal advantage demonstrate that it is not a holistic approach. I will therefore suggest a substitutive definition.

\footnotetext{
${ }^{3}$ Animals in soccer [Online forum]. Retrieved September 22, 2012, from http://www.bigsoccer.com/community/threads/animals-insoccer.829399
} 


\section{From informal advantage to the expectancy sense of advantage}

I propose that advantage, in the sense that it is connected to what is expected but yet unfulfilled, can be labeled as the expectancy sense of advantage and may be defined as follows:

Competing party A has an expectancy advantage over competing party B at a certain point of a sport competition if it is reasonable to expect at this point that $\mathrm{A}$ will have an absolute advantage over $\mathrm{B}$ at the end of the competition.

In the Berlin final, Bolt had advantage over Gay in the expectancy sense, as well as over all of the other competitors. In other words, it was reasonable to expect that Bolt would have absolute advantage at the end of the competition. This expectation was based on inductive reasoning. The world had witnessed how Bolt won the Olympic gold medal in a stunning manner in Beijing a year earlier in 2008. Bolt slowed down and spread his arms to celebrate victory before the finish line and still set a new world record of 9.69 seconds! If an athlete can set a new world record without his or her full effort, then there is much reason to believe that he or she will be a strong contender in future competitions.

The larger the gap in the predictions concerning absolute advantage, the more infallible it is to expect that a particular athlete has an expectancy advantage. Bolt's expectancy advantage over Dwain Chambers was more certain than his expectancy advantage over Gay in the Berlin final. Chambers' personal best was 9.97 seconds and Gay's personal best before the race was 9.77 seconds (IAAF, 2012). This made it reasonable to suppose that Bolt would have a greater gap in the absolute advantage over Chambers than over Gay. In other words, the athletes' personal records (and also season's best) were a basis for the interpretation that Bolt had an expectancy advantage over Chambers with higher certainty than over Gay.

Even though reasonable expectations can be in line with actual probabilities, one should remember that neither of them signifies certainty. This can be demonstrated with the example of the Daegu World Championships in 2011. Once again, Bolt had an expectancy advantage over his rivals at the beginning of 100-meter final. However, things did not go as planned. Bolt took a false start and was disqualified; therefore, he did not win the gold. It was reasonable to expect that he would outperform the other competitors, but reasonable expectations are only accurate probabilities at their best. In brief, advantage in the expectancy sense does not guarantee the winners and the losers. It only serves as a prediction about them.

The expectancy sense of advantage is extremely open to disagreement because it concerns predictions and expectations. For instance, Jamaican Asafa Powell is the former world record holder in the 100-meter dash, with a time of 9.74 seconds. His personal best is 9.72 seconds, and he has run the distance more frequently under "the borderline" of 10 seconds than any other athlete in the world ${ }^{4}$ (IAAF, 2012). Nevertheless, his best achievement in major international contests is a bronze medal from the Berlin World Championships. This makes it difficult to judge how he is going to perform in major finals. To conclude, people may not easily reach agreement about an expectancy advantage.

To summarize, advantage in the expectancy sense involves what is reasonable to predict about the absolute advantage at the end of the sporting competition. Hence, I have now provided explanations for both absolute advantage and expectancy advantage, but I have not examined their relationship to each other. I will concentrate on this matter next.

\section{Different functions of the absolute sense of advantage and the expectancy sense of advantage}

The absolute sense of advantage is the primary meaning of the concept, whereas the expectancy sense of advantage is the secondary meaning. This is based on the remark that the absolute sense is self-standing with respect to the sense of expectancy. We can say that Bolt has absolute advantage without referring to the other sense of advantage. Conversely, advantage in the expectancy sense is secondary because it is dependent or conditional upon the self-standing sense. When we say that Bolt has an advantage in the

\footnotetext{
${ }^{4}$ This pattern was determined in 2012 .
} 
expectancy sense, we refer to the primary sense; that is, we expect that Bolt is going to have an advantage in the absolute sense.

Advantage seems to be analogous with the concept of durability, since they both have the same two senses - absolute and expectative. For instance, we can examine the claim that my T-shirt is durable. If I have worn the T-shirt frequently over a 5-year period and it is still in good condition, then it is durable in the absolute sense. Had I just bought it and said that this T-shirt is durable, I am using the term in the expectancy sense. I have reason to expect that it is going to last many years based on, for example, the quality of the material. In other words, I expect the T-shirt to be durable in the absolute sense. Advantage functions in a similar manner. Usain Bolt has an advantage in the absolute sense if he has a better performance number than those of his competitors. Furthermore, he has an expectancy advantage if it is reasonable to expect that he will have a better performance number than those of his competitors at the end of the race.

Advantage in the absolute sense is a precondition of all sports competitions. As stated earlier, the absolute advantage refers to a relationship of superiority that exists between the performance numbers that are ascribed to relevant aspects of an athletic performance. If this sort of relationship did not exist, then situations like Bolt running ahead of Gay or a soccer team leading its opponent 2-0 lose their current significance and purpose. We understand these situations of leading because there is a phenomenon that I have presented as the absolute sense of advantage. Without this sense, it would be impossible to grasp the meaning of "being ahead of another" or "winning" in a sports competition context. In brief, the absolute sense of advantage is a necessary condition of sports competitions.

Advantage in the expectancy sense helps us to relate to the practice of sports competitions. It provides the nearest access to probabilities in a sporting context. For instance, at the 2008 Beijing Olympics, the Jamaican relay team had an advantage in the expectancy sense over all of the rival teams in the final men's 100-meter relay race. Spectators were expecting a gold medal and a world record. However, watching or participating in that event would have been totally different without the expectancy sense of advantage. Spectators or even competitors would have no idea regarding who was going to win or if the Jamaican team would even be able to run faster than their grandmothers. In brief, without the expectancy sense of the concept of advantage, we would be quite adrift in the realm of sports.

I have demonstrated that the absolute sense of advantage is a necessary condition of sports competitions. In contrast, advantage in the expectancy sense is dependent on the absolute sense, and its function is to make sports competitions more comprehensible to both the participants and the spectators.

\section{Conclusion}

I have argued that there are two senses of advantage in the context of sports- the absolute sense and the expectancy sense. The absolute sense depicts a relationship of superiority. A competitor has absolute advantage over his or her rival at certain points of a sports competition if he or she has a better performance number than his or her competitor at that point. The expectancy sense of advantage is a prediction about absolute advantage. A competitor has expectancy advantage over another competitor if it is reasonable to expect that he or she will have absolute advantage over his or her rival at the end of the competition. The two senses have different functions. The absolute sense of advantage is a necessary condition of every sports competition. In contrast, the expectancy sense of advantage is a tool that helps one to understand the competition. Together, they demonstrate how advantage plays a vital role in sport competitions.

Lastly, let's apply my theory of advantages to the hypothetical soccer match between the national teams of Brazil and Finland. After 80 minutes of play, Brazil has an absolute advantage over Finland, which can be seen it has better performance number of 5 goals compared to Finland's 0 goals. It also has an expectancy advantage over Finland at this moment, since it was reasonable to expect that Brazil will win the match even though Finland receives a penalty kick due to a refereeing error and could potentially score. 
I acknowledge that the penalty kick increases Finland's possibilities of victory, but according to the systematic explanation of advantage presented in this paper, the improved situation cannot be called an advantage. Instead, it might be called an enhancement. Sometimes enhancements generate advantages, but enhancements are not the focus of this paper; therefore, I will not investigate them any further in this context. My goal has been a systematic explanation of advantages, although there is a similar need for an analysis of the concept of enhancement. The explanation of advantage presented in this paper can function as model for these future endeavors.

\section{Acknowledgement}

During the writing process, I have received grants from the Department of Behavioural Sciences and Philosophy, University of Turku, and from the Turku University Foundation. The Public Choice Research Centre, University of Turku, has also supported the preparation of this manuscript. Finally, I wish to thank Juha Räikkä and Sigmund Loland.

\section{REFERENCES}

Brüggemann, G.P., Arampatzis, A., Emrich, F. \& Potthast, W. (2008). Biomechanics of double transtibial amputee sprinting using dedicated sprinting prostheses. Sports Technology, 1(4-5), 220-227. DOI: 10.1002/jst.63

Carr, C.L. (2008). Fairness and performance enhancement in sport. Journal of the Philosophy of Sport, 35(2), 193-207. DOI: $10.1080 / 00948705.2008 .9714738$.

Court of Arbitration for Sport. (2008). Pistorius v/ IAAF, award of 16 May 2008 (Arbitration CAS 2008/A/1480). Retrieved from Court of Arbitration for Sport website: http://jurisprudence.tascas.org/sites/CaseLaw/Shared\%20Documents/1480.pdf

Edwards, S.D. (2009). Should Oscar Pistorius be excluded from the 2008 Olympic Games? In E. Jespersen \& M. McNamee (Eds.), Ethics, dis/ability and sports (pp. 26-39). London, England: Routledge.

Foddy, B., Savulescu, J. (2011). Time to re-evaluate gender segregation in athletics. British Journal of Sports Medicine, 45(15), 1184-1188. DOI: $10.1136 / 1184$ bjsm.2010.071639

Gardner, R. (1995). On performance-enhancing substances and the unfair advantage argument. In W. J. Morgan \& K. V. Meier (Eds.), Philosophic inquiry in sport (2nd ed., pp. 222-31). Champaign, IL: Human Kinetics.

Hämäläinen, M. (2012). The concept of advantage in sport. Sport, Ethics and Philosophy, 6(3), 308-322. DOI: $10.1080 / 17511321.2011 .649360$

IAAF. (2009). Biomechanical analysis, 12th IAAF World Championships in Athletics Berlin, 15-23.08.2009. Retrieved from IAAF website:

http://berlin.iaaf.org/mm/document/development/research/05/30/83/20090817081546\%5fhttppostedfile\%5fwch09\%5f m100\%5ffinal\%5f13529.pdf

IAAF (2012, September 9). Top lists: 100 metres all time. Retrieved from IAAF website: http://www.iaaf.org/statistics/toplists/inout=o/age=n/season=0/sex=M/all=y/legal=A/disc=100/detail.html

Jones, C., Wilson, C. (2009). Defining advantage and athletic performance: The case of Oscar Pistorius. European Journal of Sport Science, 9(2), 125-131. DOI: 10.1080/17461390802635483

Loland, S. (1999). Justice and game advantage in sporting games. Ethical Theory and Moral Practice, 2(2), 165-183. DOI: 10.1023/A:1009960012546

Loland, S. (2002). Fair play in sport. A moral norm system. London, England: Routledge.

Tucker, R., Dugas, J. (2009, August 17). Analysis of Bolt's 9.58 world record [Web log post]. Retrieved June 3, 2013, from The Science of Sport website: http://www.sportsscientists.com/2009/08/analysis-of-bolts-958-wr.html

\section{AUTHOR'S ADDRESS: $\quad$ Mika Hämäläinen}

Public Choice Research Centre (PCRC)

Publicum, Assistentinkatu 7, 20014

University of Turku, Finland.

E-mail: mikham@utu.fi 